\title{
The Effect of Partnership Care Plan on Metabolic Control of Iraqi Diabetic Adolescents
}

\author{
Ghariba Hassanali ${ }^{1}$, Sima Mohammad Khan Kermanshahi ${ }^{*}$, DellarAnvar Kakil ${ }^{3}$ and Elaine Mordoch $^{4}$ \\ 1,2Department of Pediatric Nursing, School of Medical Sciences, Tarbiat Modares University, Tehran, Iran \\ ${ }^{2}$ Department of Nursing, School of Medical Sciences, Tarbiat Modares University, Tehran, Iran \\ ${ }^{3}$ Department of Diabetes, Erbil Hospital, Erbil, Iraq \\ ${ }^{4}$ College of Nursing, Faculty of Health Sciences, University of Manitoba, Canada
}

\begin{abstract}
Objective: This study designed and evaluated a long-term care program based on the partnership care planforthe metabolic control of diabetic adolescents in Iraq. The aim of the present study was to determine the effect of using the Partnership Care Plan on diabetic adolescences' metabolic control.

Methods: This is a quasi-experimental study, which was performed in Diabetes Center in Arbil, Iraq during 2012-2013. Forty diabetic adolescents were assigned to two groups of 20 members. The partnership care plan was applied in four stages (Motivation, Readying, Involvement, and Evaluation) with an intervention group for a period of three months. The control index for diabetes was the level of $\mathrm{HbA} 1 \mathrm{C}$ and insulin, which were measured in both groups before and after the intervention. Data were analyzed by the SPSS software (ver. 16.0) using paired-t and independent-t tests.
\end{abstract}

Results: T-test results revealed that before intervention, both groups had similar levels of $\mathrm{HbA} 1 \mathrm{C}(\mathrm{p}=0.77)$ and insulin $(p=0.10)$. However, after intervention, there was a satatistically significant difference between the two groups in the level of both $\mathrm{HbA1C}(p<0.000)$ and insulin $(p=0.02)$.

Conclusion: The results indicated that using the Partnership Care Plan in adolescents with type 1 diabetes is effective for controlling metabolism.

\section{Keywords: Diabetes; Adolescence; Partnership care plan}

\section{Introduction}

Diabetes is the most common chronic disease worldwide. The prevalence of diabetes is increasing rapidly and the World Health Organization (2003) has predicted that the number of people with diabetes throughout the world would have almost doubled worldwide, from 177 million in 2000 to 370 million 2030 [1]. This chronic disease necessitates long term behavioral and lifestyle change [2]. The number of people suffering from diabetes has increased continuously with estimates of one million and nine hundred diabetic cases reported in 2010 in the age of 20, and it is estimated that there will be more than 366 million people suffering with diabetes by 2030 [3]. This noticeable increase in the prevalence of diabetes indicates the importance of identifying effective blood sugar control methods.

There are three clinical centers for diabetes in Iraqi Kurdistan. Based on the Iraqi Kurdistan Health Department reports, diabetes is the ninth leading cause of death and the third chronic fatal disease after hypertension and cancer. There were 141,143 diabetic cases in 2008 in this region. 76,984, 43,562 and 20,678 cases in Soleymanie, Erbil and Dehuk, respectively. Iraq's population is 27 million with an estimated diabetes prevalence $7.43 \%$, roughly about 2 million cases. In Iraqi Kurdistan (a region of about 4 million population), the prevalence of type 1 diabetes is $8-10 \%$ meaning that there is one diabetic case out of every 10 people [4]. The prevalence in teenagers has been increasing during the last decade [5]. Based on estimations, there is one diabetic case per 400 to 500 teenagers in the world [6]. Typel diabetes is considered a chronic and difficult disease for teenagers and their families. As diabetes management relies on selfmanagement [7], patient education is a key intervention in promoting family health when a child is diagnosed with type 1 diabetes. The goal of patient education is to empower children and their parents to acquire knowledge and skills, and to master and control the treatment process [8]. School-age children can learn diabetes self-management skills but they need their parents to share the responsibility of diabetes management [9]. Teenagers with type 1 diabetes and their families are required to manage several insulin injections, monitor blood glucoses control, endure diet limitations and do regular physical activities. The increasing prevalence of diabetes will have a significant impact on national and individual economies as well as on individual health [10].

The cost of diabetes is estimated to be about 99 billion us $\$$ in direct and indirect medical care related to disability and early deaths [11]. The goals of diabetic patient care are to reduce complications, increase the quality of life scales, health promotion. Using the home care self-care education in diabetic patients affective in their continuous behaviors and glycemic control [12]. Nurses play an important role in the control and prevention of diabetes. Nurses need to adopt an empowering manner of education, and recognize and assess a child's readiness to learn about diabetes care and take responsibility for it [13]. Nursing care plans assist to solve parts of the patients' problems. The Partnership Care Plan is effectiveness for the primary care of

*Corresponding author: Sima Mohammad Khan Kermanshahi, Assistan Professor of Nursing, Department of Nursing, School of Medical Sciences, Tarbiat Modares University, Tehran, Iran, Tel: +982182883899; E-mail: kerman_s@modares.ac.ir

Received April 19, 2016; Accepted May 20, 2016; Published May 28, 2016

Citation: Hassanali G, Kermanshahi SMK, Kakil D, Mordoch E (2016) The Effect of Partnership Care Plan on Metabolic Control of Iraqi Diabetic Adolescents. J Diabetes Metab 7: 670. doi:10.4172/2155-6156.1000670

Copyright: (c) 2016 Hassanali G, et al. This is an open-access article distributed under the terms of the Creative Commons Attribution License, which permits unrestricted use, distribution, and reproduction in any medium, provided the original author and source are credited. 
both patients and families. The aim of this cooperation is to take the most appropriate service from the most appropriate provider, in the most appropriate place, at the right time and with minimal barriers to be patient. Collaborative care can establish contacts between the people, better relationship with the exchange of clinical information, joint training programs, and improve the out put of this approach [14]. While Kelmo developed an example of an evidence-based patient education program. Other factors supporting changes in work practices require consideration for further development of the model [15]. Therefore, we evaluated the Partnership Care plan for increasing the interaction between patient, nurse, and physician to monitor and control the conditions of diabetic patients. The specific objectives were:

- To monitor and compare insulin levels in adolescents with type 1 diabetes in the intervention and control groups. (pre- and postintervention).

- To monitor and compare the levels of HbA1C in adolescents with type 1 diabetes in the intervention and control groups (pre- and postintervention).

\section{Materials and Methods}

This research is based on a quasi-experimental study of diabetic adolescents who were referred to the diabetic centers of Erbil located in northern Iraq (Kurdistan). Subjects attending the diabetic centers of Erbil were selected through the census sampling method. All subjects were placed in either the control group (20 persons) or intervention group (20 persons). All subjects had a pre-test measure of blood sugar (BS) tests over two days; they then were randomly separated into two groups.

\section{Inclusion criteria}

- Diagnosed with type 1 diabetes for at least one year ago;

- Having the age between 12 and 20 years.

\section{Exclusion criteria}

- Having no other acute or chronic disease or illnesses.

We measured HbA1C and insulin levels as two para clinic tests. The independent and dependent variables were the Partnership Care Plan and diabetes metabolic control respectively in which the effect of Partnership Care Plan on the dependent variable was determined. The effect of the Partnership Care Plan on diabetic control for teenagers was determined by comparing the $\mathrm{HbA1C}$ levels and insulin consumption before and after the intervention in the control and intervention groups. No intervention was applied to the control group.

The Partnership Care Plan was done in the intervention group in four stages: Motivation, Readying, Involvement, and Evaluation.

\section{Motivation}

Diabetes is a chronic disease and many patients are unaware of the side-effects of their disease; they need to be motivated to become actively involved in controlling the disease. Children desire to be independent in their choices and decisions concerning diabetes management [16-18]. In this stage, the health assessment questionnaire designed based on the patients' diabetic management problems was completed patients. Thus the patients' educational needs and care management were determined. The nurse and physician discussed with the diabetic adolescents about their problems and needs as well as the necessity for long-term management of the disease.

\section{Readying}

After the motivation process, the patients were prepared to participate in the reading stage. Readying can be organized by partnership care team. The members of the team were twenty adolescents, one specialist nurse, and one physician. These meetings took place in three-four sessions lasting approximately 45-60 minutes. These meetings gave information about the complications of diabetes, empowerment, and autonomy in self-care. The specialist nurse and physician directed the meetings together.

\section{Involvement}

Involvement was defined as the continuous cooperation and active participation of all the persons at the meetings as well as patient compliance with the principles of self-care, accomplished during the follow-up partnership meetings. The partnership follow-up meetings were conducted monthly and were organized by the partnership care team. The members of the team included: five patients with mutual problems, one specialist nurse, and one physician. The educational meetings were discussion-based, and the physician and nurse answered the patients' questions. At the start of each class, the specialist nurse, as the leader of the partnership care team, assessed the patients progress by asking questions about previous meetings and offering further explanation, if necessary. The physician guided and supported the discussion.

\section{Evaluation}

Before implementation, the participants were examined with an insulin scale and HbA1C test (as a pre-test measurement in the two study groups), and the obtained results were compared using pre- and post- tests. Data were analyzed with the SPSS software (ver.16) using the independent sample t-test, paired t-test, and Chi-square test.

\section{Ethical considerations}

All participants signed written informed consent prior to their participation. For the control group that did not get any intervention, education sessions were offered by author 1 upon completion of the intervention.

\section{Results}

The Chi-square and Fischer tests showed no significant difference between the demographic properties of the participants in two study groups and their parents $(\mathrm{p}>0.05)$ (Tables 1 and 2).

The HbA1C level was decreased from 12.2 to 10.1 in the intervention group after the intervention $(p=0.000)$; however it was increased in the control group from 12.35 (pre-intervention) to 13.7 (post-intervention), and the $\mathrm{T}$-square test indicated a significant difference $(p=0.001)$. Also before the intervention, there was no significant difference in the glycosylated hemoglobin level, based on the independent t-test, between the intervention and control group $(p=0.77)$. After the intervention, a significant difference was observed in the glycosylated hemoglobin level, between the groups $(\mathrm{p}=0.000)$ (Table 3).

Insulin consumption was decreased from 60.1 to 47.15 in the intervention group, showing a significant difference before and after the intervention $(p=0.000)$. Also it was increased from 51.6 (pre-intervention) to 59.05 (post-intervention) in the control group as validated by a coupled $t$-test $(p=0.000)$. Based on the results of independent $\mathrm{t}$-test, insulin consumption showed no significant difference before the intervention between the intervention and 


\begin{tabular}{|c|c|c|c|c|c|c|}
\hline \multirow{2}{*}{$\mathrm{x}$ square } & \multicolumn{2}{|c|}{ Control } & \multicolumn{2}{|c|}{ Intervention } & \multirow{2}{*}{\multicolumn{2}{|c|}{ Group demographic data }} \\
\hline & Percent & Number & Percent & Number & & \\
\hline \multirow{3}{*}{0.49} & 65 & 13 & 75 & 15 & Student & \multirow{3}{*}{$\begin{array}{c}\text { Teenagers, } \\
\text { job }\end{array}$} \\
\hline & 35 & 7 & 25 & 5 & Non Student & \\
\hline & 100 & 20 & 100 & 20 & Total & \\
\hline \multirow{3}{*}{0.32} & 45 & 9 & 30 & 6 & $<$ guidance & \multirow{3}{*}{$\begin{array}{l}\text { Teenagers, } \\
\text { literacy }\end{array}$} \\
\hline & 55 & 11 & 70 & 14 & > guidance & \\
\hline & 100 & 20 & 100 & 20 & Total & \\
\hline \multirow{3}{*}{$\begin{array}{c}0.23 \\
\text { (Fisher) }\end{array}$} & 100 & 20 & 85 & 17 & $>10$ years & \multirow{3}{*}{$\begin{array}{l}\text { Diabetes } \\
\text { duration }\end{array}$} \\
\hline & 0 & 0 & 15 & 3 & 10 years $>$ & \\
\hline & 100 & 20 & 100 & 20 & Total & \\
\hline \multirow{3}{*}{0.74} & 40 & 8 & 45 & 9 & 3 & \multirow{3}{*}{$\begin{array}{l}\text { Times of } \\
\text { insulin } \\
\text { injection/ } \\
\text { day }\end{array}$} \\
\hline & 60 & 12 & 55 & 11 & 4 & \\
\hline & 100 & 20 & 100 & 20 & Total & \\
\hline \multirow{3}{*}{$\begin{array}{c}0.34 \\
\text { (Fisher) }\end{array}$} & 20 & 4 & 5 & 1 & Yes & \multirow{3}{*}{$\begin{array}{l}\text { Diabetes } \\
\text { record in } \\
\text { family }\end{array}$} \\
\hline & 80 & 16 & 95 & 19 & No & \\
\hline & 100 & 20 & 100 & 20 & Total & \\
\hline \multirow{3}{*}{ 1(Fisher) } & 85 & 17 & 90 & 18 & Mixed & \multirow{3}{*}{$\begin{array}{l}\text { Type of } \\
\text { insulin }\end{array}$} \\
\hline & 15 & 3 & 10 & 2 & Non Mixed & \\
\hline & 100 & 20 & 100 & 20 & Total & \\
\hline \multirow{3}{*}{0.05} & 35 & 7 & 65 & 13 & Governmental & \multirow{3}{*}{ Fathers, job } \\
\hline & 65 & 13 & 35 & 7 & $\begin{array}{c}\text { Non- } \\
\text { Governmental }\end{array}$ & \\
\hline & 100 & 20 & 100 & 20 & Total & \\
\hline \multirow{3}{*}{ 1(Fisher) } & 10 & 2 & 10 & 2 & Illiterate & \multirow{3}{*}{$\begin{array}{l}\text { Fathers, } \\
\text { literacy }\end{array}$} \\
\hline & 90 & 18 & 90 & 18 & Literate & \\
\hline & 100 & 20 & 100 & 20 & Total & \\
\hline \multirow{3}{*}{1 (Fisher) } & 85 & 17 & 18 & 90 & Housewife & \multirow{3}{*}{ Mothers, job } \\
\hline & 15 & 3 & 2 & 10 & Employer & \\
\hline & 100 & 20 & 100 & 20 & Total & \\
\hline \multirow{3}{*}{0.008} & 55 & 11 & 15 & 3 & Illiterate & \multirow{3}{*}{$\begin{array}{l}\text { Mothers } \\
\text { literacy }\end{array}$} \\
\hline & 85 & 9 & 85 & 17 & Literate & \\
\hline & 100 & 20 & 100 & 20 & Total & \\
\hline \multirow{3}{*}{ 1(Fisher) } & 90 & 18 & 85 & 17 & $\begin{array}{l}\text { Intermediate } \\
\text { and lower }\end{array}$ & \multirow{3}{*}{$\begin{array}{l}\text { Family } \\
\text { income }\end{array}$} \\
\hline & 10 & 2 & 15 & 3 & $\begin{array}{l}\text { Intermediate } \\
\text { and upper }\end{array}$ & \\
\hline & 100 & 20 & 100 & 20 & Total & \\
\hline
\end{tabular}

Table 1: Absolute and relative frequencies distribution of the research cases based on the demographic data in the intervention and control groups.

control groups $(\mathrm{p}=0.1)$ while a significant difference was seen after intervention between the two groups $(\mathrm{p}=0.02)$. As shown in Table 3 , there is an ascending trend in $\mathrm{HbAlC}$ level in $95 \%$ of the control group cases while a descending trend is observed in $100 \%$ of the intervention group. The Fisher test showed a significant difference between the intervention and control groups in this regard. Additionally, $85 \%$ and $95 \%$ of the participants have ascending and descending trends of insulin consumption in the intervention and control groups, respectively.

\section{Discussions}

The results indicated that the indexes of diabetic adolescents after intervention decreased significantly. Therefore, the Partnership Nursing Care Plan has a positive effect. Salehin et al. [16] utilized the Iranian Diabetes Association to pursue the relation between $\mathrm{HbAlC}$ and menstruation irregularity in teenage girls with type 1 diabetes and, demonstrated that diabetes duration is not significantly dependent upon $\mathrm{HbA1C}$ reduction [19]. With the ongoing duration of diabetes, teenagers may be more prepared to accept the responsibility of metabolic control of their diabetes. In addition,teenagers are expected to become less dependent on their parents and manage their illness more independently. Parents needed to adjust to the diabetes management regimen in order to support their child [20]. The role of the healthcare team is to give cognitive, emotional and concrete support to the family [21]. Parents need professional support to become more independent in the management of diabetes [20]. Children acquire diabetes-related knowledge and skills from the doctors, nurses and dieticians [22,23].

Bel et al. [24] noted that the economic and social conditions of diabetic patients are related to the appropriate management of diabetes. The diabetes history of the intervention and control groups is the same in the first order relatives (father, mother, sister, and brother) [24]. In India, $47.5 \%$ of diabetic teenagers have had at least one diabetic case in their family, and in 9.1 of them, the mentioned family member has been the first order relative [25]. Najimi et al. [26] evaluated the nutritional effect on metabolic indexes, Body Mass Index (BMI) and blood pressure in 100 adolescents with type 1 diabetes. They found that nutrition based education decreased the $\mathrm{HbA1C}$ significantly during three months in an intervention group [26]. A review of studies on the consideration of medical evidence of self-surveying blood sugar levels in managing type 1 and 2 diabetes reveals that the self-survey of blood sugar in type 1diabetes is effective in $\mathrm{HbA1C}$ reduction $[27,28]$. The findings of this present research indicated that both hypotheses of the study (insulin intake and $\mathrm{HbA1C}$ ) are important variables of metabolic control in diabetic teenagers, and can significantly differ with intervention $(\varphi=000)$. Our sample size was small, which is one of the limitations of this study.

\section{Conclusion}

The model presented in the present work can be applied to improve metabolic control of diabetes in teenagers in diabetic management centers. It uses the caring protocol in the metabolic control of diabetic teenagers. Therefore, it is recommended that this research be continued for three to five years to monitor the life style change over time. Nurses

\begin{tabular}{|c|c|c|c|c|c|}
\hline \multirow{2}{*}{$\begin{array}{c}\text { Step / HbA1C } \\
\text { Intervention } \\
\text { group }\end{array}$} & \multicolumn{2}{|c|}{ Before intervention } & \multicolumn{2}{|c|}{ After intervention } & \multirow[b]{2}{*}{ Coupled $t$} \\
\hline & Mean & $\begin{array}{l}\text { Standard } \\
\text { deviation }\end{array}$ & Mean & $\begin{array}{l}\text { Standard } \\
\text { deviation }\end{array}$ & \\
\hline & 12.2 & 1.73 & 10.1 & 1.37 & $p=0.000$ \\
\hline Control group & 12.35 & 1.49 & 13.7 & 1.08 & $p=0.001$ \\
\hline Independent t & \multicolumn{2}{|c|}{$p=0.77$} & \multicolumn{2}{|c|}{$p=0.000$} & \\
\hline $\begin{array}{l}\text { Step/insulin } \\
\text { consumption }\end{array}$ & \multicolumn{2}{|c|}{ Before intervention } & \multicolumn{2}{|c|}{ After intervention } & Coupled $\mathbf{t}$ \\
\hline \multirow[t]{2}{*}{$\begin{array}{l}\text { Intervention } \\
\text { group }\end{array}$} & Mean & $\begin{array}{l}\text { Standard } \\
\text { deviation }\end{array}$ & Mean & $\begin{array}{l}\text { Standard } \\
\text { deviation }\end{array}$ & \\
\hline & 60.1 & 17.75 & 47.15 & 14.65 & $p=0.000$ \\
\hline Control group & 51.6 & 14.21 & 59.05 & 17.72 & $p=0.000$ \\
\hline Independent t & \multicolumn{2}{|c|}{$p=0.1$} & \multicolumn{2}{|c|}{$p=0.02$} & \\
\hline
\end{tabular}

Table 2: Comparison of the mean and standard deviation of HbA1C \& insulin consumption before and after the intervention in the intervention and control group.

\begin{tabular}{|c|c|c|c|c|c|}
\hline \multirow{2}{*}{$\begin{array}{c}\text { Group/dependent } \\
\text { variable }\end{array}$} & \multicolumn{2}{|c|}{ Control } & \multicolumn{2}{c|}{ Intervention } & \multirow{2}{*}{ Fisher } \\
\cline { 1 - 5 } & Percent & Number & Percent & Number & \\
\hline HbA1C increase & $95 \%$ & 19 & $0 \%$ & 0 & \\
\hline HbA1C decrease & $5 \%$ & 1 & $100 \%$ & 20 & \multirow{2}{*}{$\mathrm{p}=0.000$} \\
\hline Total & $100 \%$ & 20 & $100 \%$ & 20 & \\
\hline Insulin increase & $85 \%$ & 17 & $5 \%$ & 1 & \\
\hline Insulin decrease & $15 \%$ & 3 & $95 \%$ & 19 & \multirow{2}{*}{$\mathrm{p}=0.000$} \\
\hline Total & $100 \%$ & 20 & $100 \%$ & 20 & \\
\hline
\end{tabular}

Table 3: Absolute and relative frequencies distribution of the research cases in respect to $\mathrm{HbA} 1 \mathrm{C}$ level and insulin consumption in the intervention and control groups. 
Citation: Hassanali G, Kermanshahi SMK, Kakil D, Mordoch E (2016) The Effect of Partnership Care Plan on Metabolic Control of Iraqi Diabetic Adolescents. J Diabetes Metab 7: 670. doi:10.4172/2155-6156.1000670

can affect changes in health behaviors by adopting an empowering manner of education that recognizes and assesses a children's readiness to learn about diabetes care and manage their illness. Nurses must also help parents and other adults to gradually shift the responsibility to children as they become adolescents.

\section{Acknowledgements}

We gratefully acknowledge the primary funding for this research from the Chancellor for Research of Tarbiat Modares University. The authors would also like to acknowledge the adolescents of this study for their willingness and ingenuousness.

S.M.K. is a member of the advisory board of Nursing Department of Tarbiat Modares University, and the coordinator of the team. She further interpreted data and drafted the manuscript.

G.H. designed and applied the Partnership Care Plan, and managed educational classes for adolescent as a nurse.

DAK. designed and applied the Partnership Care Plan as a physician. $\mathrm{He}$ prescribed insulin based on adolescents needs and provided requirements in the clinic for applying Partnership Care Plan

EM. edited the manuscript and added additional comments for consideration.

No potential conflicts of interest relevant to this article were reported.

\section{References}

1. Ozougwu JC, Obimba KC, Belonwu CD, Unakalamba CB (2013) The pathogenesis and pathophysiology of type 1 and type 2 diabetes mellitus. J. Physiol. Pathophysiol 4: 46-57

2. Monahan FD, Sands JK, Neighbors M, Marek JF, Green CJ, et al. (2007) Text book of medical surgical nursing. Chin, Mosby Press Inc.

3. Wild S, Roglic G, Green A, Sicree R, King H (2004) Global prevalence of diabetes: estimates for the year 2000 and projections for 2030. Diabetes Care 27: 1047-1053.

4. Helene AS (2012) Journal of Diabetes Skyrocketing in the Kurdistan Region of Iraq 29: 21-26.

5. Canadian Diabetes Association (2007) Incidence of diabetes type 1 diabetes in Canada.

6. Huang GH, Palta M, Allen C, LeCaire T, D'Alessio D; Wisconsin Diabetes Registry (2004) Self-rated health among young people with type 1 diabetes in relation to risk factors in a longitudinal study. Am J Epidemiol 159: 364-372.

7. Basevi V, Di Mario S, Morciano C, Nonino F, Magrini N (2011) Comment on: American Diabetes Association. Standards of medical care in diabetes--2011. Diabetes Care. Diabetes Care 34: e53.

8. Anderson RM, Funnell MM (2010) Patient empowerment: myths and misconceptions. Patient Educ Couns 79: 277-282.

9. Kelo M, Martikainen M, Eriksson E (2011) Self-care of school-age children with diabetes: an integrative review. J Adv Nurs 67: 2096-2108.

10. Azizi F, Gouya M, Vazirian P, Dollatshahi P (2008) Screening for type 2 diabetes in the Iranian national program: A primary report. East. Mediterr Health J 9: 22-27.

11. Johnson I, Young J, Lippincott Williams, Wilkins (2010) Handbook for Brunner $\&$ textbook of medical-surgical nursing $12^{\text {th }}$ edn.
12. Omidi A, Miri F, Khodaveisi M, Karami M, Mohammadi N (2014) The effect of training home care to type 2 diabetic patients on controlling blood glucose levels in patients admitted to the Diabetes Research Center of Hamadan. Scientific Journal of Hamadan Nursing \& Midwifery Faculty 22: 24-32.

13. Kelo M, Martikainen M, Eriksson E (2011) Self-care of school-age children with diabetes: an integrative review. J Adv Nurs 67: 2096-2108.

14. Mohammadi E, Rezapour R, Sistanehei F (2011) Evaluation of Long-Term Care Based on the Partnership Care Model in Quality-of-Life and Metabolic Control of Diabetic Patients. J Am Sci 7: 607-616.

15. Kelo M, Eriksson E, Eriksson I (2013) Pilot educational program to enhance empowering patient education of school-age children with diabetes. J Diabetes Metab Disord 12: 16

16. Marshall M, Carter B, Rose K, Brotherton A (2009) Living with type 1 diabetes: perceptions of children and their parents. J Clin Nurs 18: 1703-1710.

17. Newbould J, Smith F, Francis SA (2008) fine doing it on my owner: Partnerships between young people and their parents in the management of medication for asthma and diabetes. J Child Health Care 12: 116 -128.

18. Wales S, Nadew K, Crisp J (2007) Parents and school-aged childrens views on managing treatment adherence in asthma and diabetes. Neonatal, Pediatric and Child Health Nursing 10: 26-30.

19. Salehin SH, Vaseghrahimparvar F, Shahrakivahed A, AziziMoghadam A (2012) The correlation between Glycosylated Hemoglobin and menstrual cycle length in type 1 diabetic adolescents. J Jahrom Univ Med Sci 10: 9-14.

20. Baudrant M, Allenet B, Le Tallec C, Grangeat M, Calop J (2007) Educating diabetic children: integrating representations by children aged 7 to 11 and their parents. Pharm World Sci 29: 699-703.

21. Ginsburg KR, Howe CJ, Jawad AF, Buzby M, Ayala JM, et al. (2005) Parents perceptions of factors that affect successful diabetes management for their children. Pediatrics 116: 1095-1104.

22. Alderson P, Sutcliffe K, Curtis K (2006) Children as partners with adults in their medical care. Arch Dis Child 91: 300-303.

23. Lin HP, Mu PF, Lee YJ (2008) Mothers' experience supporting life adjustment in children with T1DM. West J Nurs Res 30: 96-110.

24. Bell RA, Camacho F, Goonan K, Duren-Winfield V, Anderson RT, et al. (2001) Quality of diabetes care among low-income patients in North Carolina. Am J Prev Med 21: 124-131.

25. Mahajerin A, Fras A, Vanhecke TE, Ledesma J (2008) Assessment of knowledge, awareness, and self-reported risk factors for type II diabetes among adolescents. J Adolesc Health 43: 188-190.

26. Najimi A, Azadbakht L, Hassanzadeh A, Sharifirad GH (2011) The Effect of Nutrition Education on Risk Factors of Cardiovascular Diseases in Elderly Patients with Type 2 Diabetes: A Randomized Controlled Trial. Iranian Journal of Endocrinology and Metabolism 13: 256-263.

27. Peymani M, Mohajeri Tehrani MR, Foroozanfar MH (2008) The Effect of SelfMonitoring of Blood Glucose (SMBG) on Improvement of HbA1C and Glycemic Control in Diabetic Patients. J Zahedan Univ Med Sci 10: 145-158.

28. Nyenwe E, Loganathan R, Blum S, Ezuteh D, Erani D, et al. (2007) Admissions for diabetic ketoacidosis in ethnic minority groups in a city hospital. Metabolism 56: $172-178$. 